\title{
Variable influence on the equatorial troposphere associated with SSW using ERA-Interim
}

\author{
Sourabh Bal ${ }^{1,4, *}$, Semjon Schimanke ${ }^{2}$, Thomas Spangehl ${ }^{3}$ and Ulrich Cubasch ${ }^{1}$ \\ ${ }^{1}$ Institute for Meteorology, Freie Universität, Berlin, Germany. \\ ${ }^{2}$ Swedish Meteorological and Hydrological Institute, Norrkoping, Sweden. \\ ${ }^{3}$ German Weather Service, Offenbach am Main, Germany. \\ ${ }^{4}$ Department of Physics, Swami Vivekananda Institute of Science and Technology, Kolkata, India. \\ ${ }^{*}$ Corresponding author.e-mail: sourabhbal@gmail.com
}

Sudden stratospheric warming (SSW) events are identified to investigate their influence on the equatorial tropospheric climate. Composite analysis of warming events from Era-Interim (1979-2013) record a cooling of the tropical lower stratosphere with corresponding changes in the mean meridional stratospheric circulation. A cooling of the upper troposphere induces enhanced convective activity near the equatorial region of the Southern Hemisphere and suppressed convective activity in the off-equatorial Northern Hemisphere. After selecting vortex splits, the see-saw pattern of convective activity in the troposphere grows prominent and robust.

\section{Introduction}

Sudden stratospheric warmings (SSW) are a vivid phenomenon in the polar region of the Northern Hemisphere (NH) during winter season. They are characterized by a rapid increase of the polar cap temperature (northward $60^{\circ} \mathrm{N}$ ) throughout the stratosphere and a weakening of the polar night jet. In general, a complete breakdown of the polar vortex occurs due to the rapid growth of vertically propagating planetary waves from the troposphere to the stratosphere due to the uneven land profile (Matsuno 1971). There is still a discussion going on in the research community about how to define sudden warming. According to World Meteorological Organization, a warming is minor when the polar temperature increases by a few tens of Kelvin within seven days at any stratospheric level. An event is coined as major if in addition to a reversal of the poleward temperature gradient, the zonal wind at $60^{\circ} \mathrm{N}$ in $10 \mathrm{hPa}$ becomes easterly.
Major warmings are further classified into vortex displacement and vortex split type events (Charlton and Polvani 2007). The reverse phenomenon to SSW is coined as vortex intensification (VI) and characterized by cooling of the polar cap temperature (Limpasuvan et al. 2005). The occurrence of these stratospheric vortex anomalies goes along with significant signals in the troposphere which are of opposite signs for SSW and VI. Effects are known and mostly understood for the $\mathrm{NH}$ high latitudes (Baldwin and Dunkerton 2001), whereas the impact on low latitudes is less clear. Kuroda (2008) reported that enhanced convective activity takes place in the Southern Hemisphere (SH) in the tropics after SSW and convective activity increases in the Northern Hemisphere after VI.

The polar stratospheric variability is considered to be controlled partially by several forces, e.g., Quasi Biennial Oscillation (QBO), El-Nino Southern Oscillation (ENSO), the 11-yr solar cycle and volcanic eruptions. A connection between direction

Keywords. Sudden stratospheric warming; convective activity; stratospheric vortex split events. 
of equatorial wind at $50 \mathrm{hPa}$ and $\mathrm{NH}$ stratospheric polar temperature was first established by Holton and Tan (1980). The stratospheric polar vortex tends to be warmer, weaker and more disturbed during easterly phase of QBO than during the westerly phase (Labitzke 1987). Evidence for the influence of 11-yr solar cycle on the stratosphere was provided by Labitzke et al. (2006) and Labitzke and Loon (1988). The occurrence of sudden stratospheric warming and its connection to ENSO have been recorded in several studies (Manzini et al. 2006; Butler and Polvani 2011; Richter et al. 2011). Recently, a model study by Mitchell et al. (2011a) described that the polar vortex is more excited during the warm phase of ENSO years compared to La Nina years. Additional drivers have been investigated by Schimanke et al. (2011). They show an impact of the North Atlantic ocean-atmosphere heat flux, Eurasian snow cover and the number of blockings onto the number of SSW. The stratosphere anomalies can significantly alter the climate of the toposphere through downward coupling effects for a period of more than two months after the occurrence of the SSW (Baldwin and Dunkerton 2001). The surface pressure signal shifts towards a negative pattern of the Arctic Oscillation (AO) following SSW (Cohen and Jones 2011). Study of an idealized general circulation model (GCM) by Thuburn and Craig (2000) suggested that the stratospheric meridional change can affect the diabatic heating rate of convection in the equatorial troposphere. Kodera (2006) considered 12 observed sudden warmings. Using composite analysis, he reported that due to the changes of the meridional circulation which are related to the warmings, the tropical lower stratosphere leads to cooling. The lower temperature is then responsible for the intensification of convective activity in the equatorial Southern Hemisphere and subdued convective activity in the Northern Hemisphere. A SH warming in September 2002 produced a northern see-saw of tropical convective activity due to vertical propagation of planetary waves from the troposphere with cooling of the tropospheric tropopause layer (TTL) (Kodera and Yamada 2004; Eguchi and Kodera 2007). Sridharan and Sathishkumar (2011) reported increased equatorial convection over Indonesian sector associated with SSW using observation data. In general, impacts of SSW are not only found for the tropical troposphere, but even more localized. Strong cooling over the surface takes place during the stratospheric warming events that were investigated by Resmi et al. (2013) over Indian region.

Kodera et al. (2014) tested the importance of convective clouds in the stratosphere-troposphere dynamics during major events of 2009 and 2010. They inferred that the planetary waves which arise during the warming event activate the intensified Brewer-Dobson circulation which further amplify the convective activity in the tropical SH. Analogous research was carried out utilizing a nonhydrostatic model and the result of this model study of Eguchi et al. (2014) speculate the enlarged convective activity during the development of planetary waves. The present research effort evaluates 17 warming events from 34 years of Era-Interim.

The paper is organized as follows. To explain the dynamics, we calculate the dates of the SSW and examine dynamical quantities followed by a statistical approach to extract the signal at surface levels during SSW events in section 2. Section 3 interpret the results with conclusions and discussion in section 4 .

\section{Data and method of analysis}

ERA-Interim data from 1979-2013 of The European Centre for Medium-Range Weather Forecasts (ECMWF) (Dee et al. 2011) is used in our study. More details about the datasets can be found at the ECMWF website (www.ecmwf.int). We use the ERA-Interim data for zonal wind, temperature and vertical velocity for 31 vertical levels from 1000 to $0.1 \mathrm{hPa}$. The potential impact of SSW onto the surface is plotted using top-net thermal radiation. At the top of the atmosphere the top-net thermal radiation should be identical to outgoing long wave radiation (OLR). The OLR observed by satellites have been used as a proxy by Gutzler and Wood (1990) and Sandeep and Stordal (2013) for the tropical convection. Top-net thermal radiation published by ERA-Interim is based on run times 00 and 12 hrs. Daily top-net thermal radiation is obtained from the sum of 00 and $12 \mathrm{hrs}$ datasets with 12 time-steps each. With the onset of sudden warming events, the divergence of EliassenPalm (EP) flux resultant of eddy heat and eddy momentum flux is used to indicate eddy forcing of the zonal planetary wave propagation. To investigate the propagation of planetary waves, we calculated the Eliassen-Palm flux parameters from 6-hourly daily data of ERA-Interim. Manual identification of warming dates is strenuous. Warming events are identified using the numerical scheme developed by Schimanke et al. (2013). We identified the key date of the warming events from ERA-Interim using zonal wind and temperature. This algorithm is capable to establish SSW dates from large datasets, e.g., model simulation data (Schimanke et al. 2013). The present numerical design was ameliorate from the previous algorithm developed by Charlton and Polvani (2007). According to WMO, the key date for each warming is assigned to the day when reversal of zonal wind at $10 \mathrm{hPa}$ takes place (Charlton and Polvani 2007). 
The algorithm used in our study identifies 17 warming events from Era-Interim. To examine the efficiency of our numerical scheme, we have compared the warming events computed from EraInterim with warming events analyzed by Freie Universität, Berlin (FUB). The comparison is presented in table 1 . It is evident from table 1 that the number of SSW from Era-Interim matches well with FUB. There are 18 events counted by FUB from 1979-2013 and the used algorithm computes one event less. Table 1 also suggests that the results obtained by the algorithm fits better in the beginning of the late 19th century. Thus the development of the present algorithm is an advancement in identifying the events. Monthly distribution of the SSW are also presented in table 2 , where it shows the number of SSW/year in Era-Interim. In November, there are no warming events identified from EraInterim which is well confirmed from FUB analysis. We use geopotential height values to classify each warming events into displacement and split type

Table 2. Monthly distribution of $S S W$ and the rate of occurrences ( $S S W /$ year) in brackets from Era-Interim (1979-2013).

\begin{tabular}{lc}
\hline Month & ERA-Interim \\
\hline November & $0(0.0)$ \\
December & $4(0.12)$ \\
January & $7(0.21)$ \\
February & $2(0.05)$ \\
March & $4(0.12)$ \\
\hline
\end{tabular}

Table 1. Contrast in SSW occurence from ERA-Interim using algorithm of Schimanke et al. (2013) and Freie Universität, Berlin (FUB) (Labitzke and Naujokat 2000).

\begin{tabular}{|c|c|c|}
\hline Winter & ERA-Interim & FUB \\
\hline $79 / 80$ & 2 SSWs(Mar+Mar) & $\mathrm{C}+\mathrm{F}(\mathrm{Nov}+\mathrm{Mar})$ \\
\hline $80 / 81$ & SSW(Mar) & $\mathrm{C}+\mathrm{SSW}(\mathrm{Nov}+\mathrm{Feb})$ \\
\hline $81 / 82$ & SSW(Dec) & $\mathrm{C}+\mathrm{F}(\mathrm{Dec}+\mathrm{Apr})$ \\
\hline $82 / 83$ & - & - \\
\hline $83 / 84$ & - & $\mathrm{F}(\mathrm{Mar})$ \\
\hline $84 / 85$ & $\mathrm{SSW}^{*}(\mathrm{Jan})$ & SSW(Jan) \\
\hline $85 / 86$ & - & $\mathrm{F}(\mathrm{Mar})$ \\
\hline $86 / 87$ & SSW(Jan) & SSW(Jan) \\
\hline $87 / 88$ & SSW(Dec) & $\mathrm{SSW}+\mathrm{F}(\mathrm{Jan}+\mathrm{Mar})$ \\
\hline $88 / 89$ & - & $\mathrm{F}($ Feb $)$ \\
\hline $89 / 90$ & - & - \\
\hline $90 / 91$ & - & SSW(Feb) \\
\hline $91 / 92$ & - & $\mathrm{C}$ (Nov) \\
\hline $92 / 93$ & - & - \\
\hline $93 / 94$ & - & $\mathrm{C}(\mathrm{Dec})$ \\
\hline $94 / 95$ & - & - \\
\hline $95 / 96$ & - & - \\
\hline $96 / 97$ & - & $\mathrm{C}(\mathrm{Dec})$ \\
\hline $97 / 98$ & - & - \\
\hline $98 / 99$ & SSW(Dec) & 2 SSWs(Dec+Feb) \\
\hline $99 / 00$ & SSW(Mar) & - \\
\hline $00 / 01$ & SSW(Feb) & $\mathrm{C}+\mathrm{SSW}(\mathrm{Nov}+\mathrm{Feb})$ \\
\hline $01 / 02$ & SSW(Dec) & $2 \mathrm{SSWs}(\mathrm{Dec}+\mathrm{Feb})$ \\
\hline $02 / 03$ & SSW(Jan) & SSW(Jan) \\
\hline $03 / 04$ & SSW(Jan) & SSW(Jan) \\
\hline $04 / 05$ & - & - \\
\hline $05 / 06$ & SSW(Jan) & SSW(Jan) \\
\hline $06 / 07$ & SSW(Feb) & SSW(Feb) \\
\hline $07 / 08$ & - & SSW(Feb) \\
\hline 08/09 & $\mathrm{SSW}^{*}(\mathrm{Jan})$ & SSW(Feb) \\
\hline $09 / 10$ & - & SSW(Feb) \\
\hline $10 / 11$ & - & - \\
\hline $11 / 12$ & - & - \\
\hline $12 / 13$ & $\mathrm{SSW}^{*}(\mathrm{Jan})$ & SSW(Jan) \\
\hline
\end{tabular}

Here $\mathrm{C}$ and $\mathrm{F}$ denote as Canadian and Final warmings, respectively from FUB analysis, * denotes vortex split events computed using geopotential heights in this present study. 
major stratospheric warming events. We identify vortex split events after checking the geopotential height at $10 \mathrm{hPa}$ in polar stereographic projection at least 5 days before and after the warming for all SSW events. When there is high pressure development over the North Pole on the key date, accompanied with separation of the polar vortex then we isolate these events as split events. Matured phases of these split events are often observed just after the actual warming dates for all datasets. Events with high pressure development over the North Pole without separation of the polar vortex are not considered as split events in this analysis. A split event is identified when there is a seperation of the polar vortex with high pressure over the North Pole in the vicinity of the peak day. Following this criterion, there are three split events from 17 SSW in Era-Interim. The identification of split events by Charlton and Polvani (2007) was based on an algorithm which computes the absolute vorticity on pressure surfaces as a substitute for Ertel potential vorticity. The identified split events are less in our study which might be explained by inspecting vortex splits using geopotential values at $10 \mathrm{hPa}$. Therefore, there might be inclusion of only those events which are prominent and robust. The split events computed by using the geopotential heights from Era-Interim falls in 1984/85, 2008/09 and 2012/13 winters. Vortex split events are connected with large planetary wave activity of wavenumber2 (Mitchell et al. 2015). The same three winters (1984/85, 1988/89 and 2008/09) have been identified by Harada et al. (2010) using Japanese 25-yr Reanalysis Project data. Earlier, Charlton and Polvani (2007) had identified 15 split events using NCEP-NCAR and ERA-40 datasets from 1958-2002. Comparison of split events with Charlton and Polvani (2007) yields one winter (1984/85) vortex split event in common with our classification using Era-Interim from 1979 to 2013. Thus, five additional split events (1986/87, $1987 / 88,1988 / 89,1998 / 99$ and 2000/01) identified by Charlton and Polvani (2007) are not captured in our classification using geopotential values at $10 \mathrm{hPa}$.

Sudden stratospheric warming signals are usually contaminated with some internal variability, e.g., related to the QBO signal (Baldwin and Dunkerton 2001; Taguchi 2011). In this present exercise, we have used high pass filter to compute the anomalies. High pass filter of 90 days; cutoff anything more than 90 days. Hence, we illustrate all composites using high pass filter.

The reason to select the high pass filter is due to that, it removes lower frequencies or in other words, it removes annual and semi-annual components.

Finally, we select time windows of 20 days before the key date and 30 days after the key date for each warming year. Composites are produced from the ensemble of each warming for a definite time slice with respect to the key date. To test the statistical significance, we use the Student $t$-test for each composite and for each variable of interest using the formula

$$
t=\sqrt{n} \times \frac{x}{\mathrm{s.d}},
$$

where $x$ represents the ensemble mean over all anomalies for a certain variable, s.d denotes the standard deviation and $n$ is the number of warming events.

\section{Results}

\subsection{Zonal mean temperature and zonal mean winds during stratospheric warming}

To interpret the changes in circulation around the actual date of SSW, figure 1 illustrates temporal transformation of the zonal temperature anomalies from Era-Interim between 20 days before and 10 days after the key day. In this figure, each panel is comprised of composites of 17 warming anomalies from Era-Interim. Figure 2 plots for zonal wind following similar temporal pattern as in figure 1 . In these plots, day-20, day 10 represents 20 days before and 10 days after the key day, respectively with 0 day as the key day. The polar vortex is colder and the equatorial lower stratosphere is warmer at least 20 days (figure 1) before the key date. Similar signals have been observed 3 days before the key date by Kodera (2006). Identical to zonal temperature, the polar night jet is stronger prior to SSW. From day-5, the westerly jet decelerates (figure 2) with the rise in stratospheric polar temperature (figure 1). Meanwhile, the tropical equatorial temperature in the lower stratosphere commence to dip. This lowering of tropical equatorial temperature extends to the upper troposphere from the actual day. The decrease in tropical temperature may be accounted due to momentum and heat flux transport from the mid-latitude into the pole by the vertically propagating planetary waves (Schoeberl 1978). Thus, with the expansion of the planetary waves from the troposphere, there is an acceleration of the Brewer-Dobson circulation which produces an anomalously warm polar vortex with colder tropics has been investigated by Kodera et al. (2014). When compared with figure 2 of Kodera (2006), we observe earlier damping of the polar vortex with a colder tropical upper stratosphere extending to the lower troposphere.

\subsection{Convective activity during warming events}

Figure 3 shows additional significant quantities connected with SSW from Era-Interim. These are 

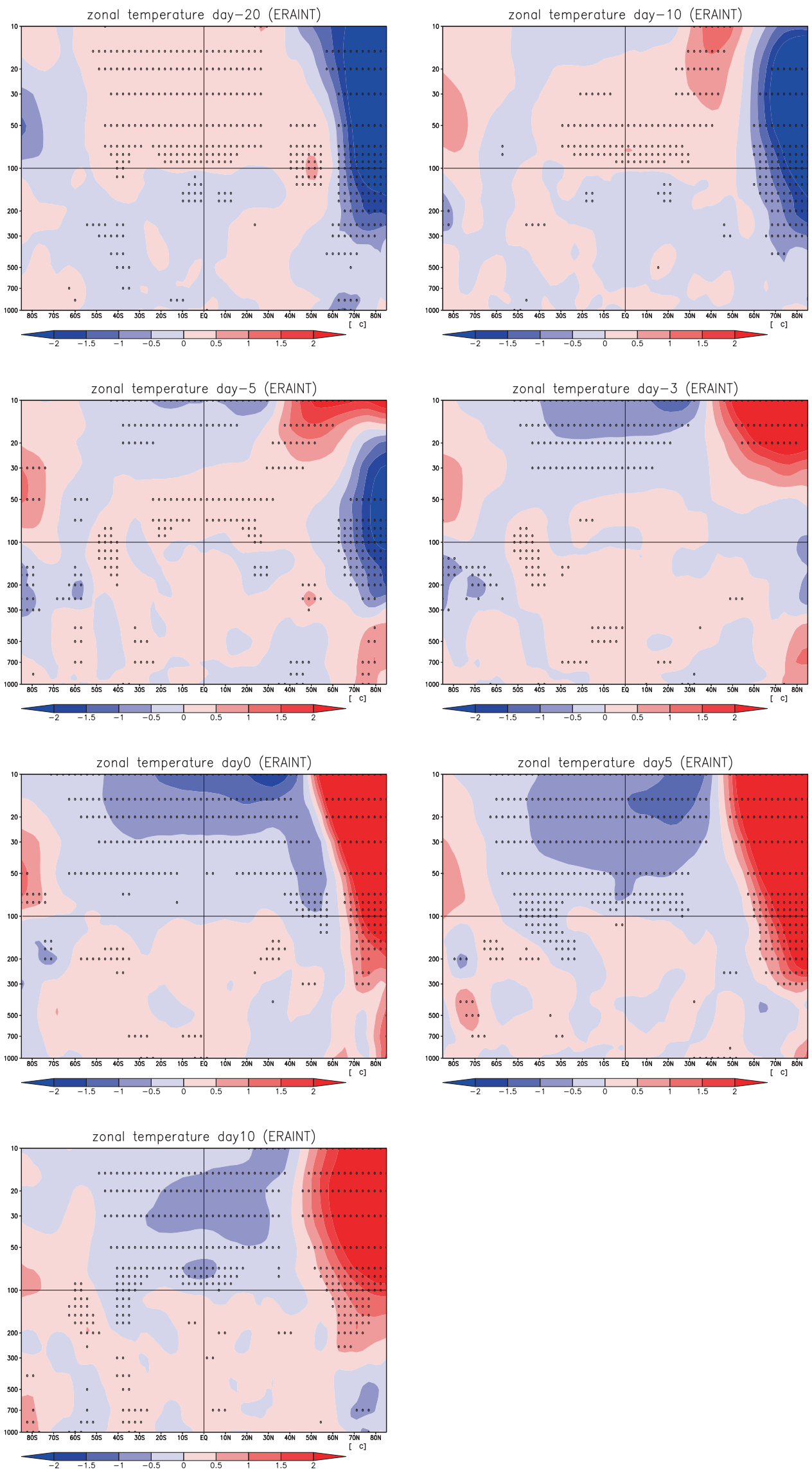

Figure 1. Meridional section of the composites based on 17 SSW events from Era-Interim showing zonal-mean temperature $\left({ }^{\circ} \mathrm{C}\right)$ for day -20 , day -10 , day -5 , day -3 , day 0 , day +5 , and day +10 . Dots represent statistical significance at $95 \%$. 

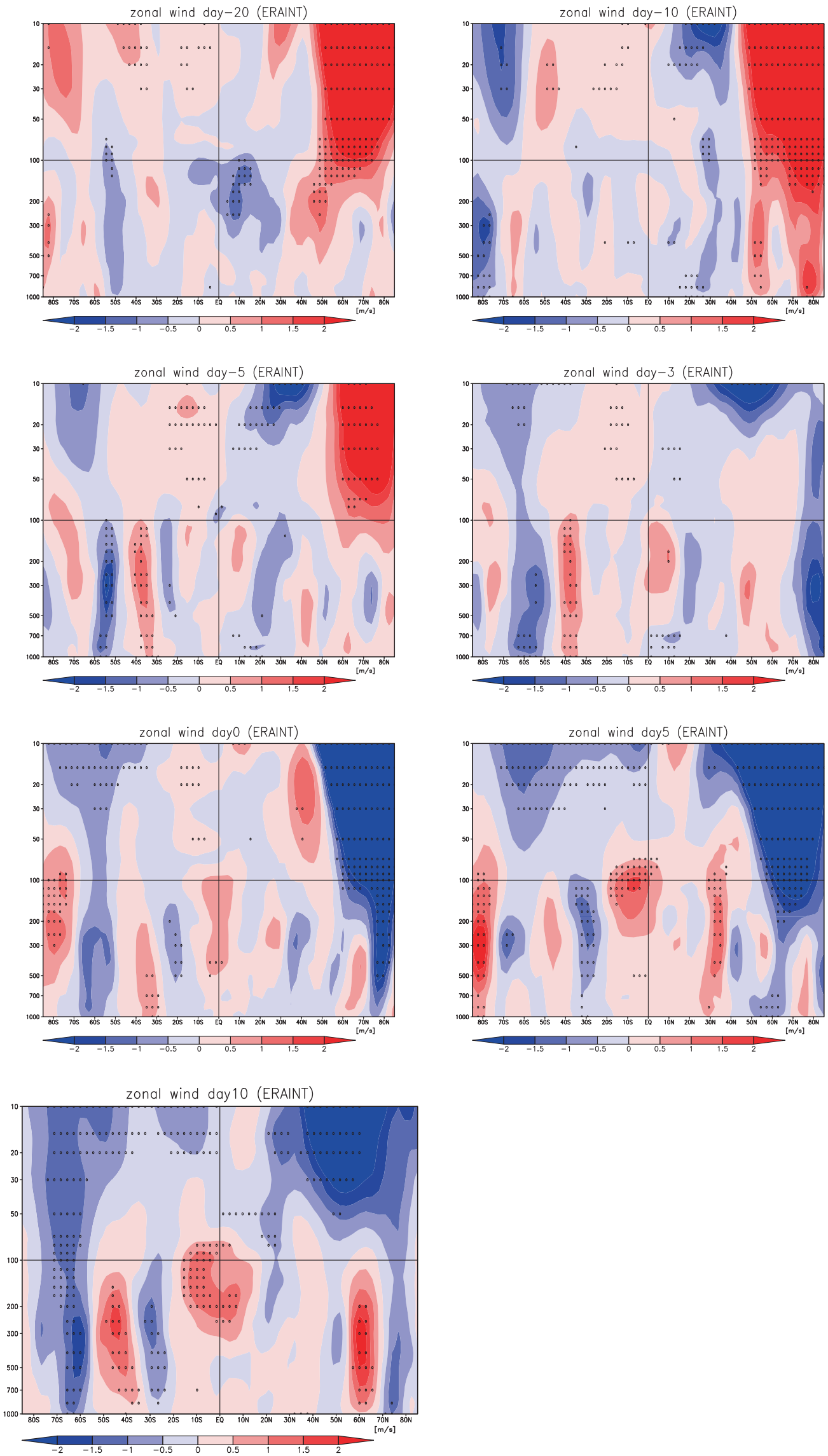

Figure 2. Meridional section based on anomalies from 17 SSW events from ERA-Interim showing zonal winds (m/s) for day-20, day-10, day-5, day-3, day 0, day+5, and day+10. Dots represent statistical significance at $95 \%$. 

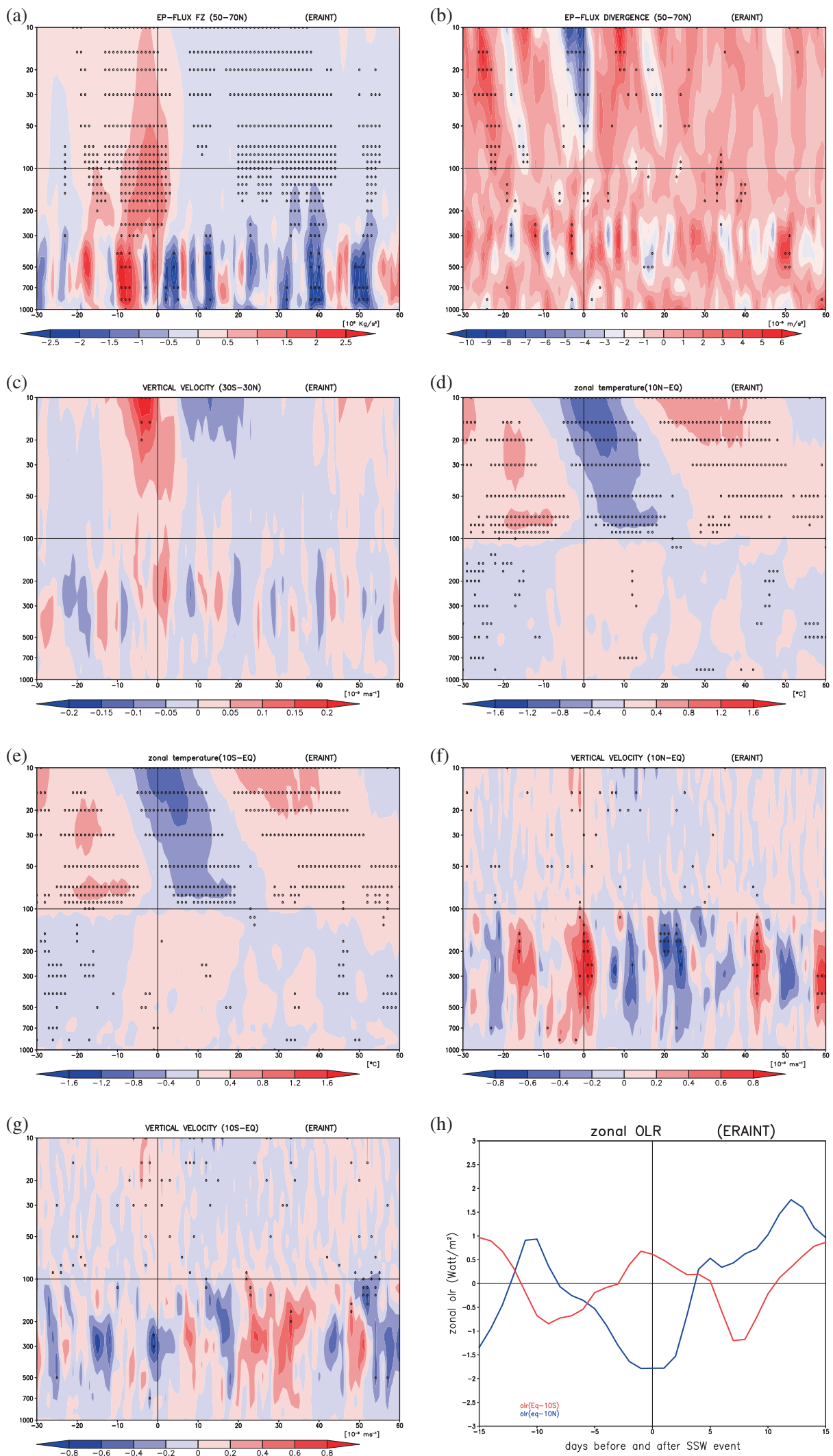

Figure 3. Composites of the time evolution of 17 events from Era-Interim. The x-axis indicates the date relative to the onset day (day 0), whereas the y-axis gives the height. In time scale 0 denotes the key date. Variables plotted to left starting from top panel: Upward EP-flux $\left(50^{\circ}-70^{\circ} \mathrm{N}\right)\left(10^{5} \mathrm{~kg} / \mathrm{s}^{2}\right)$, vertical velocity $\left(30^{\circ} \mathrm{S}-30^{\circ} \mathrm{N}\right)(\mathrm{m} / \mathrm{s})$, zonal temperature $\left(10^{\circ} \mathrm{S}-\mathrm{EQ}\right)$ $\left({ }^{\circ} \mathrm{C}\right)$, vertical velocity $\left(10^{\circ} \mathrm{S}-\mathrm{Eq}\right)(\mathrm{m} / \mathrm{s})$. Variables plotted to right starting from top: divergence $\left(50^{\circ}-70^{\circ} \mathrm{N}\right)\left(10^{-5} \mathrm{~m} / \mathrm{s}^{2}\right)$, zonal temperature $\left(10^{\circ} \mathrm{N}-\mathrm{Eq}\right)\left({ }^{\circ} \mathrm{C}\right)$, vertical velocity $\left(10^{\circ} \mathrm{N}-\mathrm{Eq}\right)(\mathrm{m} / \mathrm{s})$, zonal OLR $\left(\mathrm{Eq}-10^{\circ} \mathrm{S}\right)$ : red and $\left(\mathrm{Eq}-10^{\circ} \mathrm{N}\right)$ : dark blue $\left(\mathrm{Watt} / \mathrm{m}^{2}\right)$. Dots represent statistical significance at $95 \%$. 

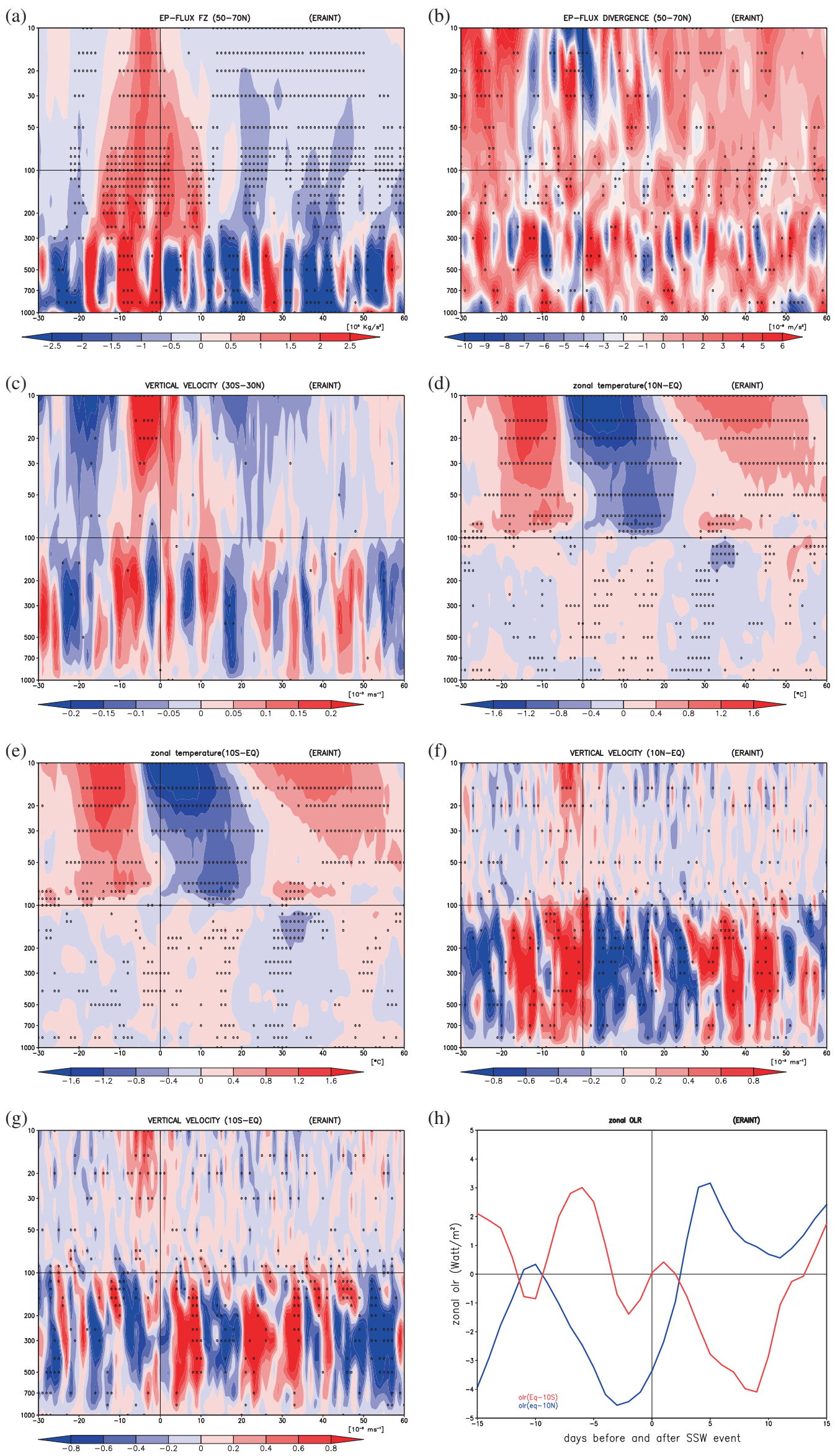

Figure 4. Same as figure 3, but with only three split events. 
the vertical component and its divergence averaged over $50^{\circ}-70^{\circ} \mathrm{N}$, vertical wind in $\mathrm{ms}^{-1}$ averaged in the three different regions of $30^{\circ} \mathrm{N}-30^{\circ} \mathrm{S}, 10^{\circ} \mathrm{N}-\mathrm{Eq}$, $10^{\circ} \mathrm{S}-\mathrm{Eq}$, the zonal temperature averaged over $10^{\circ} \mathrm{N}-\mathrm{Eq}$ and $10^{\circ} \mathrm{S}-\mathrm{Eq}$. Outgoing longwave radiation (OLR) is also plotted to identify the influence of SSW on tropical convective activity in both hemispheres. Here, all the variables are plotted from 30 days before the events till 60 days after the events where 0 denote the key date except for OLR, where -15 to 15 days from the key date is plotted. Anomalous vertical EP-flux averaged over $50^{\circ}-70^{\circ} \mathrm{N}$ in the stratosphere is strongly positive for a few days (around 3 days) before the key date (figure 3a). The EP-flux turns negative after few days of the warming events (roughly 2 days). These observations are in good agreement with similar studies of Kodera (2006), Kuroda (2008) and Kodera et al. (2014). EP-flux divergence averaged over $50^{\circ}-70^{\circ} \mathrm{N}$ in the stratosphere shows negative anomalies during the warming events (3 days before to 2 days after the events) for Era-Interim (figure $3 \mathrm{~b}$ ). The results from the EP-flux and its divergence confirm that stratospheric warming is initiated by an increased upward advancing planetary waves from the troposphere. With the increase in planetary wave forcings in the stratosphere shown as vertical EP-flux and divergence, the zonal temperature (figure $3 \mathrm{~d}$ and e) starts to decrease in the region $\left(10^{\circ} \mathrm{S}-\mathrm{Eq}\right)$ and $\left(10^{\circ} \mathrm{N}-\mathrm{Eq}\right)$ at the lower stratosphere and upper troposphere just before the warming starts. This cooling continues up to a few days after the events. The lowering of equatorial temperature in the lower stratosphere may be related to energy transfer from the midlatitude to polar region via increased wave activity through strengthening of Brewer-Dobson circulation (Kodera et al. 2014). The increase in vertical velocity in the tropical lower stratosphere begins 5 days ahead of the event and remain until 2 days after the event shown in figure 3(c). These observations may be justified as the temperature tendency in the lower stratosphere is linked to vertical velocity, particularly in this region (Kodera et al. 2014). Recently, Ueyama et al. (2013) elaborated that temperature shifts in the troposphere (below $70 \mathrm{hPa}$ ) are not correlated with vertical motion because diabatic heating due to cloud formation cancels adiabatic cooling in this domain. Thus, the positive temperature anomaly below $70 \mathrm{hPa}$ in the equatorial region analysed for the reanalysis shows no relation with the vertical velocity in the troposphere. Despite the fact that vertical velocity in the lower stratosphere is related to the temperature tendency in this region, Kodera (2006) interpreted that this incremental upwelling in the troposphere takes place along with the stratospheric change due to the decrease in temperature at $200 \mathrm{hPa}$ especially in the region $10^{\circ} \mathrm{S}-\mathrm{Eq}$, followed by upward velocity rise extending down to the surface.
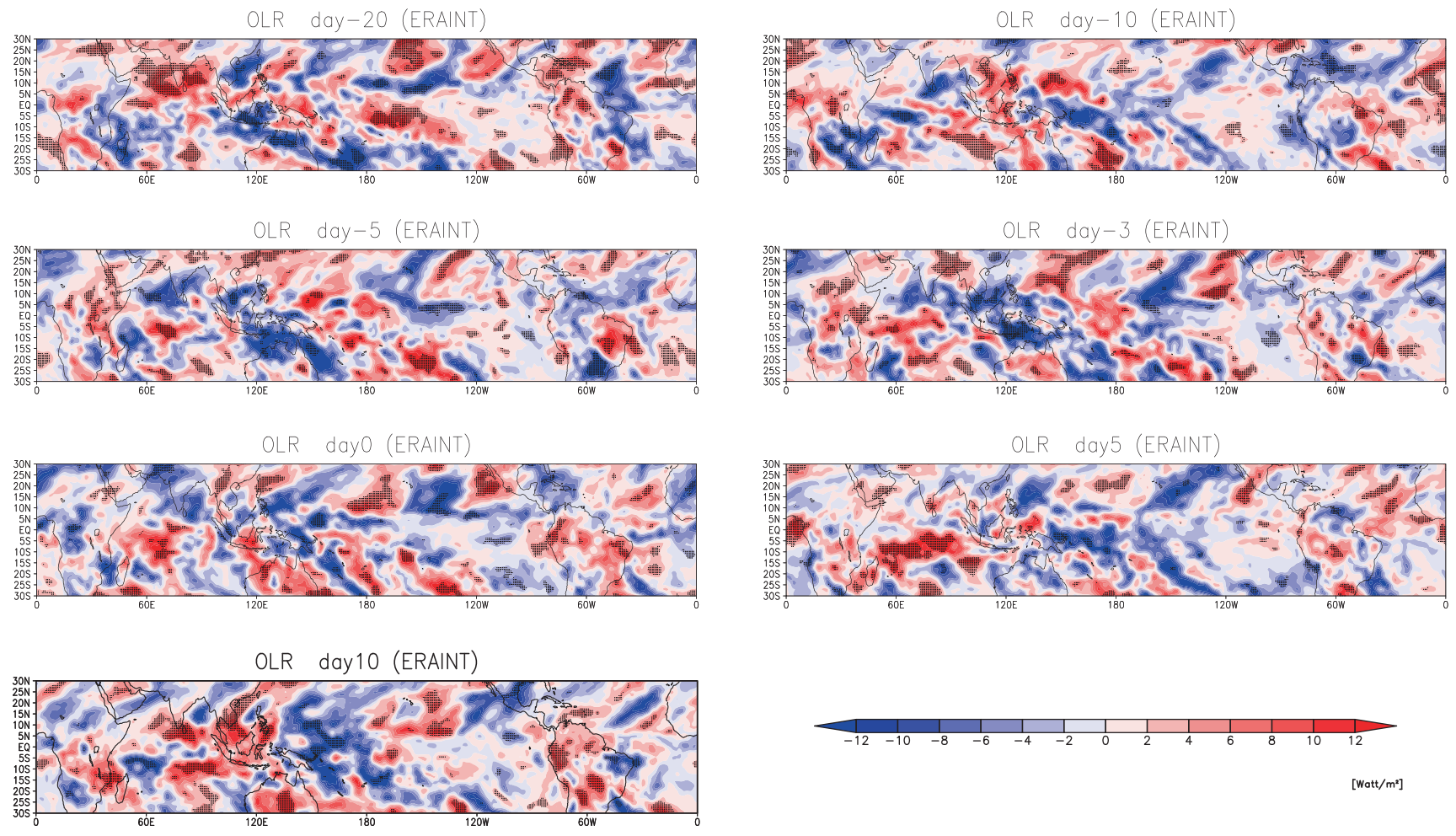

Figure 5. Latitude-longitude convective activity for 17 warming anomalies from Era-Interim showing outgoing long-wave radiation $\left(\right.$ Watt $/ \mathrm{m}^{2}$ ) for day-20, day-10, day-5, day-3, day 0, day +5 , day +10 . Dots represent statistical significance at $95 \%$. 
The accelerated vertical velocity from the surface in $10^{\circ} \mathrm{S}-\mathrm{Eq}$ is responsible for decrease in OLR, implicating enhanced convective activity in the equatorial SH after the warming (Kodera 2006). In our study, the reduced temperature in $10^{\circ} \mathrm{S}-\mathrm{Eq}$ at or below $200 \mathrm{hPa}$, which may be responsible for enhanced vertical motion from the surface is not visible in figure $3(\mathrm{~g})$. Therefore, in our study, the upward motion from the surface in the equatorial $\mathrm{SH}$ after the warming is not significant though the OLR in equatorial $\mathrm{SH}$ decrease for a short period after the warming in Era-Interim (figure $3 \mathrm{~h}$ ). The significantly increased equatorial $\mathrm{NH}$ vertical velocity (figure 3f) extending from the surface throughout the troposphere in EraInterim before the warming, justifies negative OLR before the warming. The decrease in OLR in NH after the warming is described with downward vertical velocity. The intensified vertical motion in the tropical stratosphere before the warming and enhanced convective activity after the warming may be due to the later process is lagged by almost 7 days with the former process is explained from the argument of Kodera et al. (2014).

\subsection{Convective activity during split events}

Strong warming events or split events which have more influence on the surface have been discussed in several papers (Baldwin and Dunkerton 2001; Taguchi 2011; Harada et al. 2010). In our study, 17 warmings from reanalysis constitute both the types, i.e., split or displacement. So, we classified each SSW from reanalysis into split and displacement type using geopotential height values at 10 $\mathrm{hPa}$. We have three split events from Era-Interim.

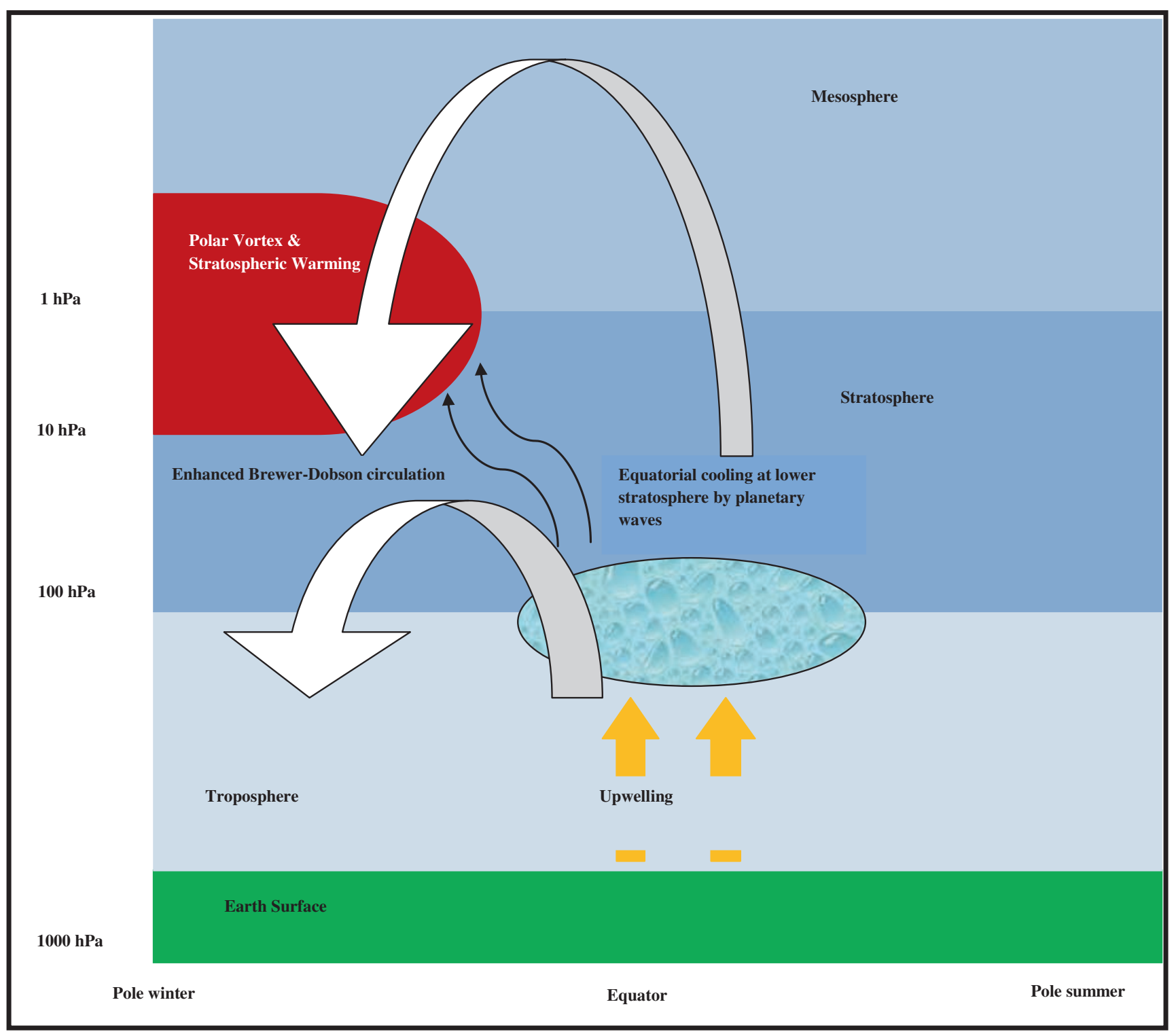

Figure 6. Schematic illustration of the influence of stratospheric warming events on the equatorial convective activity. 
The number of split events from reanalysis is too small and thus appear to be one of the constraints in this kind of study. We plotted the same quantities again similar to figure 3 considering only split events illustrated in figure 4 . The vertical component of EP-flux and its divergence with split events in Era-Interim (figure 4a and b) follows similar pattern like considering all events but the magnitude of increased vertical EP-flux anomalies increases when only vortex split events are considered. Vortex split events yield more vigorous negative divergence and sustain longer after the key day when compared to all warming events for Era-Interim. Similarly, the off-equatorial temperature anomalies at the lower stratosphere are more pronounced when split events are only counted (figure $4 \mathrm{~d}-\mathrm{e}$ ). Focussing on split events from Era-Interim shows that vertical velocity anomalies from the lower stratosphere in the tropics averaged over both the hemispheres are more robust as illustrated in figure 4(c). In Era-Interim, vertical velocity is accelerated from 10 days before the start of the event until 5 days after the event. Vortex split events from Era-Interim produce statistically significant upward velocity from the surface (figure $4 \mathrm{f}-\mathrm{g}$ ) till $100 \mathrm{hPa}$ about 10 days prior to the key date in equatorial $\mathrm{NH}$ and gets reversed after the events. In equatorial $\mathrm{SH}$, statistically significant upward velocity is noticed after 5 days of the events. The present result is well supported by the OLR plot (figure $4 \mathrm{~h}$ ), which shows decreasing OLR values in the region $\mathrm{Eq}-10^{\circ} \mathrm{S}$ and enhanced $\operatorname{OLR}\left(\mathrm{Eq}-10^{\circ} \mathrm{N}\right)$ from the prime date, suggesting enhancement of convective activity over the equatorial $\mathrm{SH}$ and suppression of convective activity in the equatorial NH.

The suppressed convective activity in $\mathrm{Eq}-10^{\circ} \mathrm{N}$ depicted as OLR begins few days prior to the prime date due to downward vertical velocity in this period. The convective process in both hemispheres changes its polarity after about a week from the key day. The convective activity in both hemispheres, i.e., enhancement in equatorial $\mathrm{SH}$ and suppression in equatorial NH from Era-Interim with only three split events admits the mechanism of Kodera (2006); Eguchi et al. (2014); and Kodera et al. (2014). The above statement hints that in order to understand the mechanism elaborately, more warming events or split events must be considered. To interpret the convective activity in the tropics, zonal values of OLR might not be sufficient to represent the fact. Therefore, the convective process during SSW have been reviewed with the horizontal distribution of OLR before and after the key date of the warming. OLR can be used as a proxy for cloud height and herewith for convective activity. Figure 5 shows the time evolution of the horizontal distribution of OLR anomalies before and after the onset of the events, respectively. In Era-Interim (figure 5), significant negative OLR values is noticed over the Maritime Continent and western Pacific before the key date and the low-value region over the Maritime Continent is weakened after the onset of the event (see also Kodera et al. (2014)).

\section{Conclusions and discussion}

Effects of Northern Hemisphere SSW are clearly visible in the equatorial stratospheric temperature in Era-Interim. The decrease in temperature in the lower stratosphere and upper troposphere which is caused by the increased wave activity from the stratosphere is well apprehended in our study. As shown in the previous papers (Kodera 2006; Kodera et al. 2014), the decrease in equatorial temperature induces changes in upward vertical motion in the equatorial troposphere resulting in enhanced convective activity in the $\mathrm{SH}$ and suppressed convective activity in the NH during SSW.

The convective process was captured by warming events from Era-Interim but for short duration. The influence of warming events on equatorial convective processes is well illustrated for vortex split events (not large in number).

The present paper primarily intends to detail the mechanism depicted in figure 6 which has already been outlined by Kodera (2006). The underlying physics state that planetary wave activity during sudden stratospheric warming induce cooling in the tropical stratosphere due to changes of the meridional circulation which manifest in an enhanced Brewer-Dobson circulation. This lower temperature brings upwelling from the troposphere specially in equatorial $\mathrm{SH}$ with accelerated vertical motion in lower stratosphere after the warming. Thus, the process execute see-saw like convective activity in equatorial SH (NH) during SSW resulting in enhanced (suppressed) see-saw convective activity in equatorial $\mathrm{SH}(\mathrm{NH})$ during SSW.

We have investigated the impact of $\mathrm{NH}$ warming events on the convective activity in the equatorial troposphere with five SSW more than Kodera (2006) using Era-Interim. Composites of all warming events reveal that during its growth, vertical EP-flux strengthens few days before the key date from the troposphere, related with negative divergence in the lower stratosphere during this period. With the advent of these warmings, in addition to reversal of the zonal wind and rise in temperature of the polar vortex, there is a negative temperature change in the equatorial lower stratosphere by increased Brewer-Dobson circulation. The negative temperature in the upper troposphere invites upwelling from the tropics. We observe upward velocity accelerated from the upper troposphere in the $30^{\circ} \mathrm{S}-30^{\circ} \mathrm{N}$ vicinity in 
Era-Interim, few days before the key date of an SSW. The strengthening of the vertical velocity from the surface executes expanded convective activity in the $\mathrm{Eq}-10^{\circ} \mathrm{S}$ region, after the ultimate date is palpable. This convective signal is for short duration and statistically insignificant. Therefore, in Era-Interim, OLR decreases and turns negative for day 5 to 10 after the event showing enhanced convective activity in the equatorial SH. The geographic distribution of OLR in Era-Interim suggests that convective processess tend to concentrate around the western Pacific region before the key date and get distributed over some range of longitudes in SH with the planetary wave activity.

SSW are classified in many ways, i.e., displacement or split types, weak or strong vortex events and major or minor warmings. Most of the earlier works (Harada et al. 2010; Kodera et al. 2014) are considered as single warming event. They concluded from this single SSW event that split or major warming events have more significant impact on the troposphere after the warming than displacement or minor event. Recently, Taguchi (2011) confirmed that SSW with noticeable shape in terms of potential vorticity in lower latitudes causes extremely lower equatorial temperature. It was also stated that classifying in terms of potential vorticity may contain both the types, i.e., splits or displacements. In our exercise, we study the convective process of the split events only and yield pronounced results. In Era-Interim, robust significant upward acceleration after the warming determines the enhanced convection in SH. In our study, the number of split events is less, therefore large numbers of strong SSW events are required to evidently support the underlying physics. As the number of SSW from observations are limited, the use of model simulation can outsource more SSW with different types. Thus, with more number of events and their different hypotheses might be proven. Additionally, further studies may evaluate a criterion to separate SSW which measures convective activity in the tropical troposphere. It is significant to note that 17 warming events from Era-Interim are not enough to produce robust convective signals during or after stratospheric warmings. Though convective activity in split events are prominent in the SH after the warming but the number of considered SSWs is too small. Consequently, the extraction of convective activity signal during warming after removing variability is a vital task.

\section{Acknowledgements}

We thank Dr. Markus Kunze for providing us the routine to calculate the EP-flux parameters.
Sourabh Bal was supported by the Erasmus Mundus (EMINTE) post-doctoral scholarship for nine months at FU, Berlin. We are grateful to Prof. $\mathrm{K}$ Krishnamoorthy, the editor and anonymous reviewer for useful and helpful comments that improved this manuscript substantially.

\section{References}

Baldwin M P and Dunkerton T J 2001 Stratospheric harbingers of anomalous weather regimes; Science 294(5542) 581-584.

Butler A H and Polvani L M 2011 El niño, la niña, and stratospheric sudden warmings: A re-evaluation in light of the observational record; Geophys. Res. Lett. 38(13).

Charlton A J and Polvani L M 2007 A new look at stratospheric sudden warmings. Part I: Climatology and modeling benchmarks; J. Clim. 20(3) 449-469.

Cohen J and Jones J 2011 Tropospheric precursors and stratospheric warmings; J. Clim. 24(24) 6562-6572.

Dee D, Uppala S, Simmons A, Berrisford P, Poli P, Kobayashi S, Andrae U, Balmaseda M, Balsamo G, Bauer P et al. 2011 The Era-Interim reanalysis: Configuration and performance of the data assimilation system; Quart. J. Roy. Meteorol. Soc. 137(656) 553-597.

Eguchi N and Kodera K 2007 Impact of the 2002, southern hemisphere, stratospheric warming on the tropical cirrus clouds and convective activity; Geophys. Res. Lett. 34(5).

Eguchi N, Kodera K and Nasuno T 2014 A global nonhydrostatic model study of a downward coupling through the tropical tropopause layer during a stratospheric sudden warming; Atmos. Chem. Phys. Discuss. 14(5) 6803-6820.

Gutzler D S and Wood T M 1990 Structure of large-scale convective anomalies over tropical oceans; J. Clim. 3(4) 483-496.

Harada Y, Goto A, Hasegawa H, Fujikawa N, Naoe H and Hirooka T 2010 A major stratospheric sudden warming event in January 2009; J. Atmos. Sci. 67(6) 2052-2069.

Holton J R and Tan H C 1980 The influence of the equatorial quasi-biennial oscillation on the global circulation at 50 mb; J. Atmos. Sci. 37(10) 2200-2208.

Kodera K 2006 Influence of stratospheric sudden warming on the equatorial troposphere; Geophys. Res. Lett. 33(6).

Kodera K and Yamada K 2004 Impact of the SH major stratospheric warming on the Hadley circulation: A case study; Papers Meteorol. Geophys. 54(3) 111-116.

Kodera K, Funatsu B, Claud C and Eguchi N 2014 The role of convective overshooting clouds in tropical stratosphere-troposphere dynamical coupling; Atmos. Chem. Phys. Discuss. 14(16) 23,745-23,761.

Kuroda Y 2008 Effect of stratospheric sudden warming and vortex intensification on the tropospheric climate; J. Geophys. Res. Atmos. 113(D15).

Labitzke K 1987 Sunspots, the qbo, and the stratospheric temperature in the north polar region; Geophys. Res. Lett. 14(5) 535-537.

Labitzke K and Loon H V 1988 Associations between the 11-year solar cycle, the QBO and the atmosphere. Part I: The troposphere and stratosphere in the northern hemisphere in winter; J. Atmos. Terr. Phys. 50(3) 197206.

Labitzke K and Naujokat B 2000 The lower arctic stratosphere in winter since 1952; Sparc Newslett. 15 11-14.

Labitzke K, Kunze M and Brönnimann S 2006 Sunspots, the $\mathrm{QBO}$ and the stratosphere in the north polar region -20 years later; Meteorologische Zeitschrift 15(3) 355-363. 
Limpasuvan V, Hartmann D L, Thompson D W, Jeev K and Yung Y L 2005 Stratosphere-troposphere evolution during polar vortex intensification; J. Geophys. Res. Atmos. 110(D24).

Manzini E, Giorgetta M, Esch M, Kornblueh L and Roeckner E 2006 The influence of sea surface temperatures on the northern winter stratosphere: Ensemble simulations with the MAECHAM5 model; J. Clim. 19(16) 3863-3881.

Matsuno T 1971 A dynamical model of the stratospheric sudden warming; J. Atmos. Sci. 28(8) 1479-1494.

Mitchell D, Gray L and Charlton-Perez A 2011a The structure and evolution of the stratospheric vortex in response to natural forcings; J. Geophys. Res. Atmos. 116(D15).

Mitchell D M, Charlton-Perez A J and Gray L J 2015 Characterizing the variability and extremes of the stratospheric polar vortices using $2 \mathrm{~d}$ moment analysis; J. Atmos. Sci. 68(6) 1194-1213.

Resmi E, Mohanakumar K and Appu K 2013 Effect of polar sudden stratospheric warming on the tropical stratosphere and troposphere and its surface signatures over the Indian region; J. Atmos. Sol.-Terr. Phys. 105 15-29.

Richter J H, Matthes K, Calvo N and Gray L J 2011 Influence of the quasi-biennial oscillation and El NiñoSouthern Oscillation on the frequency of sudden stratospheric warmings; J. Geophys. Res. Atmos. 116(D20).
Sandeep S and Stordal F 2013 Use of daily outgoing longwave radiation (OLR) data in detecting precipitation extremes in the tropics; Remote Sens. Lett. 4(6) 570-578.

Schimanke S, Körper J, Spangehl T and Cubasch U 2011 Multi-decadal variability of sudden stratospheric warmings in an AOGCM; Geophys. Res. Lett. 38(1).

Schimanke S, Spangehl T, Huebener $\mathrm{H}$ and Cubasch U 2013 Variability and trends of major stratospheric warmings in simulations under constant and increasing GHG concentrations; Clim. Dyn. 40(7-8) 1733-1747.

Schoeberl M R 1978 Stratospheric warmings: Observations and theory; Rev. Geophys. 16(4) 521-538.

Sridharan S and Sathishkumar S 2011 Observational evidence of deep convection over Indonesian sector in relation with major stratospheric warming events of 2003-04 and 2005-06; J. Atmos. Sol.-Terr. Phys. 73(17) 2453-2461.

Taguchi M 2011 Latitudinal extension of cooling and upwelling signals associated with stratospheric sudden warmings; J. Meteorol. Soc. Japan 89(5) 571-580.

Thuburn J and Craig G C 2000 Stratospheric influence on tropopause height: The radiative constraint; J. Atmos. Sci. 57(1) 17-28.

Ueyama R, Gerber E P, Wallace J M and Frierson D M 2013 The role of high-latitude waves in the intraseasonal to seasonal variability of tropical upwelling in the BrewerDobson circulation; J. Atmos. Sci. 70(6) 1631-1648. 